\title{
Lower health literacy predicts smoking relapse among racially/ethnically diverse smokers with low socioeconomic status
}

\author{
Diana W Stewart ${ }^{1 *}$, Miguel Ángel Cano ${ }^{1}$, Virmarie Correa-Fernández ${ }^{1}$, Claire Adams Spears ${ }^{2}$, Yisheng Li \\ Andrew J Waters ${ }^{4}$, David W Wetter ${ }^{1,5}$ and Jennifer Irvin Vidrine ${ }^{1}$
}

\begin{abstract}
Background: Nearly half of U.S. adults have difficulties with health literacy $(\mathrm{HL})$, which is defined as the ability to adequately obtain, process, and understand basic health information. Lower HL is associated with negative health behaviors and poor health outcomes. Racial/ethnic minorities and those with low socioeconomic status (SES) are disproportionately affected by poor HL. They also have higher smoking prevalence and more difficulty quitting smoking. Thus, lower HL may be uniquely associated with poorer cessation outcomes in this population.

Methods: This study investigated the association between HL and smoking cessation outcomes among 200, low-SES, racially/ethnically diverse smokers enrolled in smoking cessation treatment. Logistic regression analyses adjusted for demographics (i.e., age, gender, race/ethnicity, relationship status), SES-related characteristics (i.e., education, income), and nicotine dependence were conducted to investigate associations between $\mathrm{HL}$ and smoking relapse at the end of treatment (3 weeks post quit day).

Results: Results indicated that smokers with lower HL (score of $<64.5$ on the Rapid Estimate of Adult Literacy in Medicine [REALM]) were significantly more likely than those with higher $\mathrm{HL}$ (score of $\geq 64.5$ on the REALM) to relapse by the end of treatment, even after controlling for established predictors of cessation including demographics, SES, and nicotine dependence $(\mathrm{OR}=3.26 ; 95 \% \mathrm{Cl}=1.14,9.26)$.

Conclusions: Findings suggest that lower HL may serve as an independent risk factor for smoking relapse among low-SES, racially/ethnically diverse smokers enrolled in treatment. Future research is needed to investigate longitudinal relations between $\mathrm{HL}$ and cessation outcomes and potential mechanisms of this relationship.
\end{abstract}

Keywords: Health literacy, Smoking cessation, Health disparities

\section{Background}

For over 90 million U.S. adults, difficulty with health literacy (HL) interferes with the capacity to obtain, process, and understand basic health information needed to make appropriate healthcare decisions [1,2]. Thus, HL is a conceptually-distinct construct from poor knowledge regarding smoking-related health risks. Individuals with lower HL are more likely to engage in unhealthy behaviors (e.g., unhealthy eating, poor medication adherence), and they have less access to prevention and treatment programs

\footnotetext{
* Correspondence: DWStewart@mdanderson.org

${ }^{1}$ The Department of Health Disparities Research, The University of Texas MD Anderson Cancer Center, Houston, TX, USA

Full list of author information is available at the end of the article
}

$[3,4]$. Compared to individuals with higher HL, those with lower HL are more likely to have poor health status and health outcomes [4]. They are also more likely to be of low socioeconomic status (SES) and racial/ethnic minorities [5]. Because smoking is the leading behavioral risk factor contributing to social disparities in the incidence and mortality of disease [6-10], there is a critical need to understand how difficulty with HL might impact smoking cessation outcomes. It is possible that HL is an important, but overlooked, factor in understanding tobacco-related health disparities.

To date, little is known about the potential impact of low HL on smoking and cessation outcomes. Sudore and colleagues reported a significant relationship between lower 
HL and current smoking status among elderly adults [11]; however, Baker et al. found no association between lower HL and smoking status in a different sample of older adults [12]. Arnold and colleagues reported no association between HL and smoking status among low-income, pregnant women, yet found that lower HL was significantly associated with lower levels of smoking risk knowledge and fewer negative smoking-related attitudes [13]. A more recent study found that among low-SES, racially/ethnically diverse smokers, lower HL was significantly associated with certain established predictors of smoking relapse (i.e., nicotine dependence, stronger positive and weaker negative smoking outcome expectancies, less smoking health risk knowledge, and lower smoking risk perceptions), even after controlling for demographic and SESrelated characteristics known to predict relapse i.e., age, gender, race/ethnicity, education, income, relationship status; [14].

These findings highlight the need for studies to investigate the association between HL and cessation outcomes, particularly among racially/ethnically diverse smokers. Smokers with lower HL are more difficult to recruit and retain in treatment studies e.g., [15]. Furthermore, smokers with lower $\mathrm{HL}$ who do enroll in treatment may have trouble understanding oral and written treatment materials, and may fail to tell others about these difficulties due to shame and embarrassment see $[16,17]$. Research is needed to gain a better understanding of the association between HL and smoking cessation outcomes and potential mechanisms of this association. Such studies would help to inform and improve smoking prevention and cessation interventions targeting individuals with HL difficulties, and should ultimately contribute to reducing tobacco-related health disparities.

The purpose of the present study was to examine the impact of HL on smoking cessation outcomes among low-SES, racially/ethnically diverse smokers enrolled in cessation treatment. Based on prior research, it was hypothesized that lower HL would be associated with poorer cessation outcomes, even after controlling for demographic (i.e., age, gender, race/ethnicity, relationship status) and SES-related characteristics (i.e., education, income) and nicotine dependence.

\section{Method}

\section{Participants and eligibility criteria}

Participants $(\mathrm{N}=200)$ were daily smokers enrolled in a larger smoking cessation treatment study (Project PRISM) designed to investigate changes in smoking risk perceptions throughout the process of quitting smoking. The main outcome paper for this trial is currently in preparation. All participants were recruited in Houston, TX via media (e.g., paid advertisements, public service announcements) and community outreach (e.g., staff visits to healthcare setting and health fairs, distribution of study flyers). Eligible participants smoked $\geq 5$ cigarettes per day for the last year, had expired carbon monoxide (CO) levels of $\geq 8$ parts per million ( $\mathrm{ppm}$ ), were able to read at $\geq 6$ th grade reading level, and were between 18-65 years old. Exclusion criteria were: contraindication for nicotine patch use, current diagnosis of substance abuse or dependence, use of nicotine replacement therapy or bupropion products other than the nicotine patches provided by the study, regular use of tobacco products other than cigarettes, enrollment of other household members in the study, and pregnancy or lactation.

\section{Procedure}

Study staff contacted interested smokers by phone. After receiving a detailed description of the study, potential participants provided verbal informed consent and were screened for eligibility. Eligible participants were scheduled for in-person baseline orientation visits during which the study was further described, written consent was obtained, eligibility was finalized, and baseline measures were completed. All questionnaires were administered in private interview rooms via the Questionnaire Design System (QDS), a computer-administered self-report interview system that includes audio and visual scripts (i.e., participants are able to hear and read questions).

Participants attended five in-person study visits (i.e., baseline, week 0 [quit day], weeks $1-3$ post-quit). Smoking cessation treatment for all participants comprised four weeks of nicotine patch therapy, four brief in-person counseling sessions based on the Treating Tobacco Use and Dependence Clinical Practice Guideline [18], and self-help materials. This study was approved by the Institutional Review Board at the University of Texas MD Anderson Cancer Center.

\section{Measures}

Demographics and indicators of socioeconomic status were assessed at baseline and included age, gender, race/ ethnicity, education, total annual household income, and relationship status. Responses for the following variables were categorized as: gender (male, female), race/ethnicity (Non-Latino White, Black, Other), education (< high school degree vs. $\geq$ high school degree/GED), income $(<\$ 20,000$ vs. $\geq \$ 20,000$ ), and relationship status (married/living with a partner vs. not married/not living with a partner). Age was treated continuously.

Health literacy was measured at baseline with the Rapid Estimate of Adult Literacy in Medicine (REALM), a word recognition test that that assesses whether individuals have the ability to read and correctly pronounce 66 common medical words and lay terms for body parts [19]. Individuals are instructed to read through the list of words and to pronounce as many words as possible. 
Scoring is based on standard dictionary pronunciation rules. The sum of words read correctly is translated into one of four grade level estimates $\left(0-18,<4^{\text {th }}\right.$ grade; $19-44$, $4^{\text {th }}-6^{\text {th }}$ grade; $45-60,7^{\text {th }}-8^{\text {th }}$ grade; $\geq 61, \geq 9^{\text {th }}$ grade). The REALM is one of the most commonly used measures of HL [20]. It has excellent test-retest reliability and is highly correlated with comprehensive literacy measures such as the Wide Range Achievement Test-Revised and tests of functional HL such as the Test of Functional Health Literacy in Adults $[19,21,22]$.

Nicotine dependence was assessed at baseline via the heaviness of smoking index (HSI), which is comprised of two items: self-reported average number of cigarettes smoked per day and time to first cigarette upon waking [23]. The HSI is a good indicator of nicotine dependence, has fair internal consistency [24], and predicts smoking relapse [25].

Biochemically-verified ( $\mathrm{CO}<8 \mathrm{ppm})$, self-reported continuous smoking abstinence was assessed at the end of treatment (3 weeks post quit). Continuous abstinence was defined as no smoking, not even a puff, since the quit date. Self-reported abstinence was assessed one week, two weeks, and three weeks following the quit day, and was biochemically verified at each of the three assessment points using expired air carbon monoxide levels $(\mathrm{CO}<$ $8 \mathrm{ppm}$ ). Participants who reported abstinence from smoking at any of these assessments but had expired air $\mathrm{CO}$ levels $>8 \mathrm{ppm}$ were classified as smoking. The Society for Nicotine and Tobacco Subcommittee on Biochemical Verification [26] has indicated that a CO reading of 8$10 \mathrm{ppm}$ distinguishes nonsmokers from smokers.

\section{Statistical analyses}

Bivariate correlations examined associations among $\mathrm{HL}$, demographics, nicotine dependence, and cessation outcomes. Logistic regression analyses adjusted for demographics (i.e., age, gender, race/ethnicity, relationship status) and SES (i.e., education, income) and nicotine dependence were used to examine associations between $\mathrm{HL}$ and smoking relapse.

\section{Results}

Participants had a mean age of 46.1 years $(S D=9.7)$ and were primarily female and non-Latino White (see Table 1 ). REALM scores were quite high (mean $=62.3 ; \mathrm{SD}=5.4$; range $=41-66$ ). Therefore, consistent with multiple previous studies, we dichotomized HL [14,27-29] based on a median split (lower $\mathrm{HL}<64.5$ vs. higher $\mathrm{HL} \geq 64.5$ ). Lower HL was associated with being Black and having lower education and income $(p s<.05)$. See Table 2 for correlations among study variables.

Logistic regression analyses adjusted for demographics, SES, and nicotine dependence indicated that smokers with lower (vs. higher) HL were significantly more likely
Table 1 Participant characteristics

\begin{tabular}{lc}
\hline Variable & $\begin{array}{c}\text { Total sample (N= 200), } \\
\text { Mean (SD) or No. (\%) }\end{array}$ \\
\hline Age (years; range 18-69) & $46.1(9.7)$ \\
Gender & \\
Female & $115(57.5)$ \\
Male & $85(42.5)$ \\
Race & \\
Non-Latino White & $102(51.0)$ \\
Black & $89(44.5)$ \\
Other & $9(4.5)$ \\
Total annual household income & \\
$<$ \$20,000 & $89(44.5)$ \\
$\geq \$ 20,000$ & $106(53.0)$ \\
Missing & $5(2.5)$ \\
Educational level & \\
$<$ High school degree/GED & $64(32.0)$ \\
$\geq$ High school degree/GED & $136(68.0)$ \\
Relationship status & \\
Married/living with partner & $58(29.0)$ \\
Not married/not living with partner & $142(71.0)$ \\
REALM & $62.3(5.4)$ \\
HSI & $3.7(1.3)$ \\
Ressation outcome & \\
Abstinent & $170(85.0)$ \\
\hline Note. & $30(15.0)$ \\
\hline
\end{tabular}

Note. REALM = Rapid Estimate of Adult Literacy in Medicine. $\mathrm{HSI}=$ Heaviness of Smoking Index.

to relapse by the end of treatment $(\mathrm{OR}=3.26 ; 95 \% \mathrm{CI}=$ 1.14, 9.26; See Table 3).

\section{Discussion}

To our knowledge, this is the first known investigation of the association between HL and smoking cessation outcomes among low-SES, racially/ethnically diverse smokers enrolled in cessation treatment. As hypothesized, smokers with lower HL were more likely than smokers with higher $\mathrm{HL}$ to relapse following cessation treatment. Importantly, this association held after adjusting for established predictors of relapse including nicotine dependence, demographics, and SES (i.e., education, income). Findings provide preliminary support for lower HL as an independent risk factor for smoking relapse among low-SES, racially/ethnically diverse smokers.

Results indicated that lower HL was associated with being Black and having lower education and income. These findings are consistent with the 2003 National Assessment of Adult Literacy [1,30], which indicated that lower HL was associated with male gender, older age, racial/ethnic 
Table 2 Correlations among study variables

\begin{tabular}{|c|c|c|c|c|c|c|c|c|c|}
\hline Variables & REALM & Age & Gender & Race & Income & Education & Relationship status & $\mathrm{HSI}$ & Smoking relapse \\
\hline REALM & - & & & & & & & & \\
\hline Age & -.09 & - & & & & & & & \\
\hline Gender $^{\mathrm{a}}$ & .11 & -.13 & - & & & & & & \\
\hline Race $^{b}$ & $-32^{* *}$ & -.02 & -.05 & - & & & & & \\
\hline Income ${ }^{c}$ & $.22^{* *}$ & .08 & $-.17^{*}$ & $-.21^{* *}$ & - & & & & \\
\hline Education $^{d}$ & $.28^{* *}$ & .12 & -.13 & $-.14^{*}$ & $.25^{* *}$ & - & & & \\
\hline Relationship Status ${ }^{\mathrm{e}}$ & .02 & .01 & $-.34^{* *}$ & -.10 & $.38^{* *}$ & .13 & - & & \\
\hline $\mathrm{HSI}$ & -.10 & $.20^{* *}$ & .03 & $-.15^{*}$ & -.04 & $-.22^{* *}$ & .06 & - & \\
\hline Smoking Relapse ${ }^{f}$ & $-.18^{*}$ & -.01 & .14 & .14 & $-.18^{*}$ & -.14 & $-.22^{* *}$ & .06 & - \\
\hline
\end{tabular}

Note. REALM = Rapid Estimate of Adult Literacy in Medicine. HSI = Heaviness of Smoking Index. ${ }^{\mathrm{a} G e n d e r: ~} 0=$ male, $1=$ female; ${ }^{\mathrm{b}}$ Race: $0=$ non-Latino White, $1=$ Black/Other racial/ethnic minority; ${ }^{\top}$ Total Annual Household Income: $0=<\$ 20,000,1 \geq \$ 20,000 ;{ }^{d}$ Education: $0=<$ high school degree/GED, $1 \geq$ high school degree/GED; ${ }^{e}$ Relationship Status: $0=$ not married/not living with partner; $1=$ married/living with partner; ${ }^{\mathrm{f}}$ Smoking Relapse: $0=$ abstinent, $1=$ relapsed.

${ }^{*} p<.05 ;{ }^{* *} p<.01$.

minority status, and SES-related characteristics such as lower education and income. They are also in line with results from numerous other studies [11,14,31-33]. It is noteworthy that lower (vs. higher) HL smokers in this study were more than three times as likely to relapse, even after controlling for the effects of established predictors of relapse. These results support prior research suggesting

Table 3 Logistic regression analyses of the association between health literacy and smoking relapse, controlling for age, gender, race/ethnicity, income, education, relationship status, and nicotine dependence

\begin{tabular}{lcc}
\hline Variable & $\begin{array}{c}\text { Odds ratio } \\
\text { (OR) }\end{array}$ & $\begin{array}{c}\text { 95\% Confidence } \\
\text { interval (Cl) }\end{array}$ \\
\hline Health Literacy & 3.26 & $1.15-9.26^{*}$ \\
Age & .98 & $.93-1.23$ \\
Gender & & \\
$\quad$ Female & .46 & $.17-1.23$ \\
$\quad$ Male & 2.13 & $.79-5.71$ \\
Race/Ethnicity & & \\
Black & .52 & $.20-1.37$ \\
$\quad$ Non-Latino White & 1.93 & $.73-5.13$ \\
Income & & $.28-2.53$ \\
$\quad<$ 20,000 & .84 & $.39-3.45$ \\
$\geq \$ 20,000$ & 1.16 & $.19-2.23$ \\
Education & & $.43-5.16$ \\
$\quad<$ High school degree/GED & .65 & $.78-6.23$ \\
$\geq$ High school degree/GED & 1.49 & $.17-1.34$ \\
Relationship Status & & $.86-1.79$ \\
Married/living with partner & 2.21 & \\
Not married/not living with partner & .47 & 1.24 \\
Nicotine Dependence & & \\
\hline
\end{tabular}

Note. The odds ratios are adjusted for all demographic covariates (i.e., age, gender, race/ethnicity, income, education, relationship status, nicotine dependence). ${ }^{*} p<.05$. that HL is a crucial SES-related factor essential in understanding health disparities $[4,14,32,34]$.

In addition to being associated with a greater likelihood of smoking relapse, prior research has found that lower HL is associated with higher nicotine dependence, more positive and fewer negative expectancies about the consequences of smoking, less knowledge about smoking health risks, and lower smoking risk perceptions $[13,14]$. These findings highlight the need for efforts to increase awareness about the impact of HL difficulties on smoking, and potentially other, poor health behaviors. Healthcare providers should be trained to communicate clearly with patients about the health consequences of smoking, and to offer treatments that do not require high HL. Regardless of HL level, providers should utilize plain language, visual aids (e.g., pictographs), and techniques such as the teach-back method to convey smoking health risks [33,35]. Notably, research is needed to investigate potential mechanisms underlying the association between HL and cessation outcomes among lowSES, racially ethnically diverse smokers. Such findings could be useful in the development of cessation interventions targeting smokers with $\mathrm{HL}$ difficulties, and thereby help to reduce tobacco-related health disparities.

The present study has several limitations. First, the larger study required that eligible participants have at least a sixth grade reading level. This eligibility criterion resulted in a range of scores on the REALM that was skewed toward the higher end of the HL continuum, and individuals with the lowest levels of health literacy were not well represented in the study. However, it is notable that this eligibility criterion resulted in the exclusion of only six individuals screened. This phenomenon is consistent with prior research suggesting that smokers with lower HL might be more difficult to recruit and retain in treatment studies e.g., [15]. Due to the restricted range of the REALM, we were unable to use the traditional 
cut-off points, and dichotomized the REALM based on a median split. Notably, despite this restricted range, a significant association between $\mathrm{HL}$ and smoking relapse emerged. Given this restricted range, it is possible that the association between HL and smoking relapse may have been underestimated, and future studies are needed to examine this association among smokers with levels of HL that are lower than those observed in the current study. Nevertheless, it is important to note that the 95\% confidence interval was relatively wide $(1.15-9.26)$, suggesting that this finding should be interpreted cautiously.

An additional limitation is that long-term cessation outcome data was not collected. Future research should replicate and extend this work, and investigate longitudinal relations of HL and cessation outcomes using longer follow-up periods. Studies should also investigate associations between HL and cessation outcomes using alternate measures of HL, such as the Chew HL items [36]. In addition, such associations should be examined among smokers not enrolled in cessation treatment. Finally, as previously noted, future studies should examine potential mechanisms underlying relations between low $\mathrm{HL}$ and poor cessation outcomes. Gaining a better understanding of the mechanisms through which HL influences cessation will help identify treatment targets in this population, improve current cessation interventions, and ultimately reduce tobacco-related health disparities and disease burden.

\section{Conclusions}

This is the first study that we know of to investigate the association between $\mathrm{HL}$ and smoking cessation outcomes in a sample of low-SES, racially/ethnically diverse smokers enrolled in cessation treatment. Results indicated that lower HL smokers were more than three times as likely to relapse as smokers with higher HL, even after controlling for the effects of established predictors of relapse (e.g., education, income). Findings provide preliminary support for HL as an independent predictor of smoking relapse, and an important factor in understanding tobaccorelated health disparities.

\section{Competing interests}

The authors declare that they have no competing interests.

\section{Authors' contributions}

The data used in this manuscript are from a grant awarded to JIV. AJW, YL, and DWW were co-investigators on the grant and contributed heavily to the conceptualization and design of the overall project from which the data emanated. YL assisted with data analysis and interpretation. DWS drafted the manuscript and contributed to data analysis. All authors helped edit and refine the manuscript and assisted with conceptualization of the overall analytic plan. All authors read and approved the final manuscript.

\section{Acknowledgements}

This research is supported in part by grants from the Centers for Disease Control and Prevention (K01CD000193), the National Cancer Institute (R25T (A57730), and the University of Texas MD Anderson's Cancer Center Support
Grant CA016672, and the Latinos Contra el Cancer Community Networks Program Center Grant U54CA153505. This work was also supported in part by a faculty fellowship from the University of Texas MD Anderson Cancer Center's Duncan Family Institute for Cancer Prevention and Risk Assessment.

\section{Author details}

${ }^{1}$ The Department of Health Disparities Research, The University of Texas MD Anderson Cancer Center, Houston, TX, USA. ${ }^{2}$ The Department of Psychology, The Catholic University of America, Washington, DC, USA. ${ }^{3}$ The Department of Biostatistics, The University of Texas MD Anderson Cancer Center, Houston, TX, USA. ${ }^{4}$ The Department of Medical and Clinical Psychology, Uniformed Services University of the Health Sciences, Bethesda, MD, USA ${ }^{5}$ The Department of Psychology, Rice University, Houston, TX, USA.

Received: 14 January 2014 Accepted: 10 July 2014

Published: 14 July 2014

\section{References}

1. Kutner M, Greenberg E, Jin Y, Paulsen C: The health literacy of America's adults: Results from the 2003 National Assessment of Adult Literacy. Washington DC: US Department of Education, National Center for Educational Statistics; 2006

2. United States Department of Health and Human Services: Healthy People 2010, With understanding and improving health and objectives for improving health. 2nd edition. Washington DC: US Government Printing Office; 2000.

3. Michielutte R, Alciati MH, el Arculli R: Cancer control research and literacy. J Health Care Poor Underserved 1999, 10(3):281-297.

4. Berkman ND, Sheridan SL, Donahue KE, Halpern DJ, Crotty K: Low health literacy and health outcomes: An updated systematic review. Ann Intern Med 2011, 155(2):97-107.

5. Kutner M, Greenberg E, Baer J: A first look at the literacy of America's adults in the 21st century. Washington DC: U.S. Department of Education, National Center for Education Statistics; 2005.

6. Ward E, Jemal A, Cokkinides V, Singh GK, Cardinez C, Ghafoor A, Thun M: Cancer disparities by race/ethnicity and socioeconomic status. CA Cancer J Clin 2004, 54(2):78-93.

7. Wardle J, Steptoe A: Socioeconomic differences in attitudes and beliefs about healthy lifestyles. J Epidemiol Community Health 2003, 57(6):440-443.

8. Mokdad AH, Marks JS, Stroup DF, Gerberding JL: Actual causes of death in the United States, 2000. JAMA 2004, 291(10):1238-1245.

9. Vidrine $\mathrm{Jl}$, Reitzel LR, Wetter DW: The role of tobacco in cancer health disparities. Curr Oncol Rep 2009, 11:475-481.

10. Vidrine Jl, Reitzel LR, Wetter DW: Smoking and health disparities. Curr CardiovasC Risk Rep 2009, 3:403-408.

11. Sudore RL, Mehta KM, Simonsick EM, Harris TB, Newman AB, Satterfield S, Rosano C, Rooks RN, Rubin SM, Ayonayon HN, Yaffe K: Limited literacy in older people and disparities in health and healthcare access. J Am Geriatr Soc 2006, 54(5):770-776.

12. Baker DW, Wolf MS, Feinglass J, Thompson JA, Gazmararian JA, Huang J: Health literacy and mortality among elderly persons. Arch Intern Med 2007, 167(14):1503-1509.

13. Arnold CL, Davis TC, Berkel HJ, Jackson RH, Nandy I, London S: Smoking status, reading level, and knowledge of tobacco effects among lowincome pregnant women. Prev Med 2001, 32(4):313-320.

14. Stewart DW, Adams CE, Cano M, Correa-Fernandez V, Li Y, Waters AJ, Wetter DW, Vidrine Jl: Associations between health literacy and established predictors of smoking cessation. Am J Public Health 2013, 103:e43-e49.

15. Ahluwalia JS, Richter K, Mayo MS, Ahluwalia HK, Choi WS, Schmelzle KH, Resnicow K: African American smokers interested and eligible for a smoking cessation clinical trial: predictors of not returning for randomization. Ann Epidemiol 2002, 12(3):206-212.

16. Johnson VR, Jacobson KL, Gazmararian JA, Blake SC: Does social support help limited-literacy patients with medication adherence? A mixed methods study of patients in the Pharmacy Intervention for Limited Literacy (PILL) study. Patient Educ Couns 2010, 79(1):14-24.

17. Parikh NS, Parker RM, Nurss JR, Baker DW, Williams MV: Shame and health literacy: The unspoken connection. Patient Educ Couns 1996, 27(1):33-39.

18. Fiore MC: US public health service clinical practice guideline: Treating tobacco use and dependence. Respir Care 2000, 45(10):1200-1262. 
19. Davis TC, Crouch MA, Long SW, Jackson RH, Bates P, George RB, Bairnsfather LE: Rapid assessment of literacy levels of adult primary care patients. Family Medicine 1991, 23(6):433-435.

20. Berkman ND, Sheridan SL, Donahue KE, Halpern DJ, Viera AJ, Crotty K, Holland A, Brasure M, Lohr KN, Harden E, Tant: Health literacy interventions and outcomes: An updated systematic review. In Evidence Report/Technology Assesment No. 199 (Prepared by RTI International - University of North Carolina Evidence-Based Practice Center, under contract No. 290-200710056-1), AHRQ Publication Number 11-E006 edition. Rockville: Agency for Healthcare Research and Quality; 2011.

21. Davis TC, Byrd RS, Arnold CL, Auinger P, Bocchini JA Jr: Low literacy and violence among adolescents in a summer sports program. J Adolesc Health 1999, 24(6):403-411.

22. Wilson FL, McLemore R: Patient literacy levels: a consideration when designing patient education programs. Rehabil Nurs 1997, 22(6):311-317.

23. Kozlowski LT, Porter CQ, Orleans CT, Pope MA, Heatherton T: Predicting smoking cessation with self-reported measures of nicotine dependence: FTQ, FTND, and HSI. Drug Alcohol Depend 1994, 34(3):211-216.

24. Etter J-F: A comparison of the content-, construct-, and predictive validity of the cigarette dependence scale and the Fagerstrom test for nicotine dependence. Drug Alcohol Depend 2005, 77(3):259-268.

25. Baker TB, Piper ME, McCarthy DE, Bolt DM, Smith SS, Kim S-Y, Colby S, Conti D, Giovino GA, Hatsukami D, Hyland A, Krishnan-Sarin S, Niaura R, Perkins $\mathrm{KA}$, Toll BA: Time to first cigarette in the morning as an index of ability to quit smoking: Implications for nicotine dependence. Nicotine Tob Res 2007, 9(Suppl 4):S555-S570.

26. Society for Nicotine and Tobacco Subcommittee on Biochemical Verification: Biochemical verification of tobacco use and cessation. Nicotine Tob Res 2002, 4:149-159.

27. Fortenberry JD, MCFarlane MM, Hennessy M, Bull SS, Grimley DM, St Lawrence J, Stoner BP, VanDevanter N: Relation of health literacy to gonorrhoea related care. Sex Transm Infect 2001, 77(3):206-211.

28. Lillie SE, Brewer NT, O'Neill SC, Morrill EF, Dees EC, Carey LA, Rimer BK: Retention and use of breast cancer recurrence risk information from genomic tests: The role of health literacy. Cancer Epidemiol Biomarkers Prev 2007, 16(2):249-255.

29. Lindau ST, Tomori C, Lyons T, Langseth L, Bennett CL, Garcia P: The association of health literacy with cervical cancer prevention knowledge and health behaviors in a multiethnic cohort of women. Am J Obstet Gynecol 2002, 186(5):938-943.

30. Kutner $\mathrm{M}$, Greenberg E, Jin Y, Boyle B, Hsu Y, Dunleavy E: Literacy in everyday life: Results from the 2003 National Assessment of Literacy. Washington DC: US Department of Education, National Center for Education Statistics; 2007.

31. Howard DH, Sentell T, Gazmararian JA: Impact of health literacy on socioeconomic and racial differences in health in an elderly population. J Gen Intern Med 2006, 21(8):857-861.

32. Paasche-Orlow MK, Wolf MS: Promoting health literacy research to reduce health disparities. J Health Commun 2010, 15(Suppl 2):34-41.

33. Williams MV, Baker DW, Parker RM, Nurss JR: Relationship of functional health literacy to patients' knowledge of their chronic disease: A study of patients with hypertension and diabetes. Arch Intern Med 1998, 158(2):166-172.

34. Williams DR, Collins C: U.S. socioeconomic and racial differences in health: Patterns and explanations. Annu Rev Sociol 1995, 21:349-386.

35. Kripalani S, Weiss BD: Teaching about health literacy and clear communication. J Gen Intern Med 2006, 21(8):888-890.

36. Chew LD, Bradley KA, Boyko EJ: Brief questions to identify patients with inadequate health literacy. Family Med 2004, 36(8):588-594.

doi:10.1186/1471-2458-14-716

Cite this article as: Stewart et al.: Lower health literacy predicts smoking relapse among racially/ethnically diverse smokers with low socioeconomic status. BMC Public Health 2014 14:716.

\section{Submit your next manuscript to BioMed Central and take full advantage of:}

- Convenient online submission

- Thorough peer review

- No space constraints or color figure charges

- Immediate publication on acceptance

- Inclusion in PubMed, CAS, Scopus and Google Scholar

- Research which is freely available for redistribution

Submit your manuscript at www.biomedcentral.com/submit
() Biomed Central 